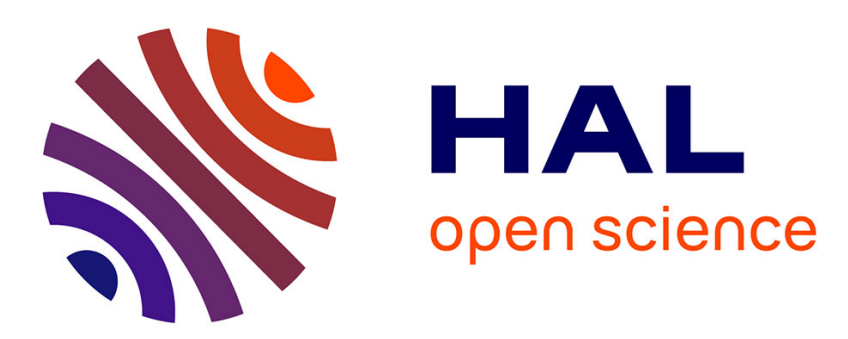

\title{
Répertoire des textes législatifs et réglementaires publiés pendant les mois de décembre 1984, janvier et février
} 1985

Francis Meyer

\section{- To cite this version:}

Francis Meyer. Répertoire des textes législatifs et réglementaires publiés pendant les mois de décembre 1984, janvier et février 1985. 1985, pp.337-338. 10.4267/2042/21818 . hal-03423614

\section{HAL Id: hal-03423614 \\ https://hal.science/hal-03423614}

Submitted on 10 Nov 2021

HAL is a multi-disciplinary open access archive for the deposit and dissemination of scientific research documents, whether they are published or not. The documents may come from teaching and research institutions in France or abroad, or from public or private research centers.
L'archive ouverte pluridisciplinaire HAL, est destinée au dépôt et à la diffusion de documents scientifiques de niveau recherche, publiés ou non, émanant des établissements d'enseignement et de recherche français ou étrangers, des laboratoires publics ou privés. 


\section{RÉPERTOIRE DES TEXTES LÉGISLATIFS ET RÉGLEMENTAIRES PUBLIÉS PENDANT LES MOIS DE DÉCEMBRE 1984, JANVIER ET FÉVRIER 1985}

\section{CHASSE}

- Questions écrites avec réponse - Sénat

Réglementation de la chasse des animaux nuisibles, M. François.

(J.O. $n^{\circ} 485$ (Q.) du 8 décembre 1984, p. 1964).

D.F.C.I.

- Réponses des ministres aux questions Assemblée Nationale

Bois et forêts (incendies), M. Tourné.

(J.O. $n^{\circ} 48$ A.N. du 3 décembre 1984, p. 5291).

\section{FISCALITÉ FORESTIÈRE}

- Décrets

Décret $n^{\circ}$ 84-1247 du 28 décembre 1984 relatif aux suspensions de perception des taxes sur les produits forestiers définis aux articles 1613 et 1618 bis du code général des impôts.

(J.O. du 30 décembre 1984, p. 4156)

Décret $n^{\circ}$ 85-158 du 31 janvier 1985 instituant une taxe parafiscale sur les pâtes, papiers, cartons et celluloses.

(J.O. des 4-5 février 1985, p. 1528)

Décret $n^{\circ}$ 85-187 du 7 février 1985 relatif aux suspensions de perception des taxes sur les produits forestiers définis aux articles 1613 et 1618 bis du cocle général des impôts.

(J.O. du 9 février 1985, p. 1739)
- Arrêtés

Arrêté du 31 janvier 1985 fixant les taux et les modalités d'assiette et de recouvrement, de gestion et d'utilisation de la taxe parafiscale sur les pâtes, papiers et cartons.

(J.O. des 4-5 février 1985, p. 1529)

\section{FORÊT PRIVÉE}

\section{- Arrêtés}

Arrêté du $1^{\text {er }}$ février 1985 modifiant l'arrêté du 4 juillet 1967 relatif aux modalités du contrôle financier sur les centres régionaux de la propriété forestière.

(J.O. du 5 mars 1985, p. 2729)

\section{O.N.F.}

\section{- Arrêtés}

Arrêté du 13 février 1985 autorisant l'Office national des Forêts à étendre ses activités d'exploitation en régie dans les forêts domaniales de la Région Haute-Normandie.

(J.O. du 2 mars 1985 p. 2635)

\section{PÊCHE FLUVIALE}

- Décrets

Décret $n^{\circ}$ 85-16 du 3 janvier 1985 portant modification du décret $n^{\circ} 58-874$ du $16 \mathrm{sep}$ - 


\section{F. MEYER}

tembre 1958 modifié relatif à la pêche fluviale.

(J.O. du 4 janvier 1985, p. 118)

\section{- Arrêtés}

Arrêté du 11 décembre 1984 relatif aux périodes d'interdiction de la pêche au saumon. (J.O. du 6 janvier 1985, p. 197)

Arrêté du 31 décembre 1984 relatif aux taux de la taxe piscicole.

(J.O. du 26 janvier 1985, p. 1129)

\section{POLITIQUE FORESTIÈRE}

\section{- Projets de loi}

Renvoi en Commission de la production et des échanges du projet de loi $n^{\circ} 2563$ relatif à la gestion, la valorisation et la protection de la forêt.

(J.O. D.P. A.N. $\mathrm{n}^{0} 1$, du 24 janvier 1985, p. 25)

M. Roger Duroure, nommé Rapporteur du projet de loi relatif à la gestion, à la valorisation et à la protection de la forêt ( $n^{\circ}$ 2563) au nom de la Commission de la production et des échanges.

(J.O. D.P. A.N. $n^{\circ} 2$ du 25 janvier 1985, p. 42)

\section{PROTECTION DE LA NATURE}

- Réponses des ministres aux questions Assemblée Nationale.

Bois et forêts (pollution et nuisances), M. Eissinger.

(J.O. $\mathrm{n}^{\circ} 48$ A.N. du 3 décembre 1984, p. 5287).

P. MEYER

\section{COMMUNIQUÉ}

\section{UNE NOUVELLE REVUE : \\ LA REVUE DOCUMENTAIRE DU CENTRE TECHNIQUE DU BOIS}

Nous avons reçu rècemment le premier numéro d'une nouvelle revue éditée par le Centre technique du bois et de l'ameublement (10, avenue de Saint-Mandé, 75012 Paris).

Cette revue propose tous les deux mois, tous les èlèments concernant la documentation parue dans le monde entier sur le bois et l'ameublement, présentés sous forme de revue de presse, revue de sommaires et analyses des articles sélectionnés.

Elle renseigne également sur les nouveautés en matière de normalisation, de traduction, de publications du C.T.B., sur les acquisitions récentes en bibliothèque, enfin sur le calendrier des manifestations mondiales intéressant le bois et l'ameublement pour les mois à venir.

Tout abonné bénéficiera d'un tarif préférentiel pour la fourniture de photocopies et l'achat de traductions, correspondant à une remise de $20 \%$. Le prix de l'abonnement pour 6 numéros est de $450 \mathrm{~F}$ H.T. pour la France et $600 \mathrm{~F}$ pour l'étranger. 